\title{
Double sellar floor sign: a clue of pituitary tumor
}

\author{
Yu-Chieh Yang ${ }^{1} \cdot$ Chih-Chien Sung ${ }^{1}$
}

Received: 3 June 2016/ Accepted: 26 June 2016/Published online: 1 July 2016

(C) SIMI 2016

A 26-year-old man presented to the emergency department (ED) with nausea, vomiting, and epigastric pain for 1 week. Physical examination was notable for mild pale conjunctiva and epigastric tenderness. Pertinent laboratory investigation showed severe hyponatremia $(106 \mathrm{mmol} / \mathrm{L})$, while serum osmolality was recorded as $224 \mathrm{mOsm} / \mathrm{kg}$ (reference range 275-295 $\mathrm{mOsm} / \mathrm{kg}$ ) and urine osmolality was $313 \mathrm{mOsm} / \mathrm{kg}$ (reference range 300-900 mOsm $/ \mathrm{kg}$ ). Hormone assays revealed high prolactin at above $1000 \mathrm{ng} /$ $\mathrm{mL}$ (reference range $2.1-17.7 \mathrm{ng} / \mathrm{mL}$ ), but low LH level at $0.44 \mathrm{mIU} / \mathrm{mL}$ (reference range $1.5-9.3 \mathrm{mIU} / \mathrm{mL}$ ); relative low TSH at $1.22 \mathrm{uIU} / \mathrm{mL}$ (reference range $0.25-5.0 \mathrm{uIU} /$ $\mathrm{mL}$ ); low free $\mathrm{T} 4$ level at $0.76 \mathrm{ng} / \mathrm{dL}$ (reference range $0.8-2 \mathrm{ng} / \mathrm{dL}$ ); low testosterone level at $13 \mathrm{ng} / \mathrm{ml}$ (reference range $241-827 \mathrm{ng} / \mathrm{dL}$ ); and low plasma cortisol level at $0.44 \mu \mathrm{g} / \mathrm{dL}$ (reference range $4.3-22.4 \mu \mathrm{g} / \mathrm{dL}$ ) with low adrenocorticotropic hormone level at below $5 \mathrm{pg} / \mathrm{mL}$ (reference range $0.1-46.0 \mathrm{pg} / \mathrm{mL}$ ), indicating panhypopituitarism except for prolactin.

Lateral skull radiograph showed enlargement of the pituitary fossa and uneven bony structure of the sella turcica with poor alignment of the anterior fossa and sphenoid wings, so called the double sellar floor sign (Fig. 1a), indicating an intrasellar mass or parasellar lesion. Magnetic resonance (MR) T2-weighted sagittal image of brain demonstrates a tumor $(2.8 \mathrm{~cm} \times 2.8 \mathrm{~cm} \times 3.8 \mathrm{~cm})$ presented with an enlarged pituitary gland and hemorrhage

Chih-Chien Sung

sungchihchien@gmail.com

1 Division of Nephrology, Department of Medicine, Tri-Service General Hospital, National Defense Medical Center, Number 325, Section 2, Cheng-Kung Road, Neihu 114, Taipei, Taiwan, ROC (a fluid-fluid level with dependent low-intensity area representing liquefied hematoma) (Fig. 1c), and MR T2weighted coronal image shows asymmetric expansion of the sellar floor secondary to uneven tumor growth (Fig. 1d). Formal assessment of visual fields showed superior bitemporal quadrantanopia. Tumor resection with an endoscopic transnasal transsphenoid approach has been performed, and the histologic pathology finding is compatible with prolactinoma with hemorrhage consistent with pituitary apoplexy. After surgery, the patient's course was uneventful, and the serum prolactin level decreased to $20 \mathrm{ng} / \mathrm{mL}$.

Pituitary apoplexy is a rare neurosurgical emergency with the clinical characteristics of sudden onset of vomiting, headache, visual disturbance, altered consciousness, and hypopituitarism that can occur due to infarction or hemorrhage of a pre-existing pituitary adenoma. Deficient vascular supply due to tumor compression or alteration in perfusion pressure when the tumor outgrows its blood supply lead to ischemic necrosis and secondary hemorrhage of the pituitary tumor. The reported incidence of pituitary apoplexy is $0.6-9.1 \%$ of surgically treated pituitary adenomas [1-3]. Surgical intervention with transsphenoidal surgery is reserved for that pituitary apoplexy with progression of neurological defect, including consciousness deterioration, impaired visual function [4], and failure of medical treatment with normoprolactinemia or important reduction in tumor size [5]. In this patient, the development of hyponatremia was caused by hypopituitarism with adrenal insufficiency secondary to pituitary prolactinoma hemorrhage.

The double sellar floor sign, resulting from asymmetric and uneven expansion of the pituitary adenoma, seen on the lateral skull film study is a key clue to the pituitary lesion. Pituitary apoplexy should be kept in mind when 
Fig. 1 a Lateral skull radiograph shows the enlargement of the pituitary fossa with a sloping floor. The floor appears as a double line (black arrows). b Normal morphology of the sella turcica as shown on a lateral skull radiograph (black arrow head). c MR T2-weighted sagittal image reveals a fluid-fluid level (white arrow) with high intensity (xanthochromic fluid) and low intensity (liquefied hematoma). d MR T2-weighted coronal image shows

asymmetric expansion of the sellar floor (white arrow head) secondary to uneven tumor growth
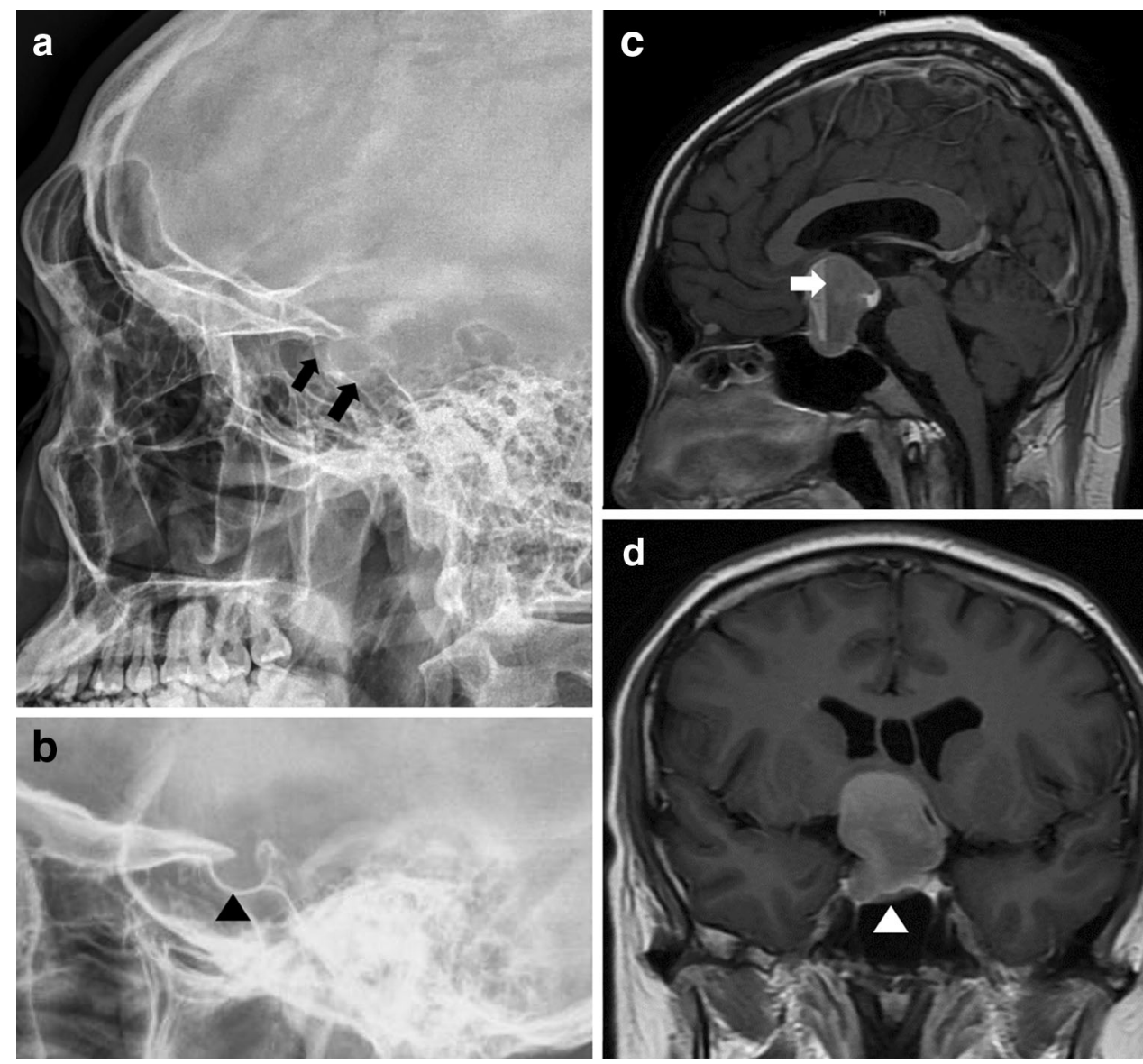

patients present with sudden headache, vomiting, visual impairment, and meningismus, which is caused by the enlargement of the pituitary gland and tumor that compress vessels and surrounding structures $[1,2]$. Clinicians should be familiar with the abnormal radiographic anatomy of the sella turcica to recognize the endocrinologic emergency. In conclusion, the double sellar floor sign plays a distinct role in early detection of pituitary tumor and even life-threatening pituitary apoplexy, and it may help to shorten the diagnostic time to avoid catastrophic complications when a patient presents with the clinical signs and symptoms of pituitary apoplexy and hyponatremia.

\section{Compliance with ethical standards}

Conflicts of interest The authors declare that they have no conflict of interest.

Statement of human and animal rights All procedures performed in studies involving human participants were in accordance with the ethic standards of institutional and/or national research committees and with the 1964 Helsinki Declaration and its later amendments or comparable ethic standards.
Informed consent Informed consent was obtained from all individual participants included in the study.

\section{References}

1. Randeva HS, Schoebel J, Byrne J, Esiri M, Adams CB, Wass JA (1999) Classical pituitary apoplexy: clinical features, management and outcome. Clin Endocrinol (Oxf) 51:181-188

2. Sally J, Eric R (2009) Pituitary apoplexy: evaluation, management, and prognosis. Curr Opin Ophthalmol 20:456-461

3. Murad-Kejbou S, Eggenberger E (2009) Pituitary apoplexy: evaluation, management, and prognosis. Curr Opin Ophthalmol 20:456-461

4. Juraschka K, Khan OH, Godoy BL, Monsalves E, Kilian A, Krischek B, Ghare A, Vescan A, Gentili F, Zadeh G (2014) Endoscopic endonasal transsphenoidal approach to large and giant pituitary adenomas: institutional experience and predictors of extent of resection. J Neurosurg 121:75-83

5. Rogers A, Karavitaki N, Wass JA (2014) Diagnosis and management of prolactinomas and non-functioning pituitary adenomas. BMJ 349:g5390 